\title{
PROGRAMA DE PREPARAÇÃO PARA A APOSENTADORIA: UMA POLÍTICA DE DESENVOLVIMENTO HUMANO
}

\author{
Lúcio Ricardo Hiurko Felippe ${ }^{1}$; \\ Hermelina Maria Sandmann"; \\ Maria Eliza Merhy ${ }^{1}$; Soledad Fernandez ${ }^{1}$; \\ Yara Lucia Mazziotti Bulgacov ${ }^{2}$
}

\section{RESUMO}

Atualmente, o processo de envelhecimento da população mundial tem despertado o interesse no desenvolvimento de iniciativas voltadas à "terceira idade". Em 1995, as mudanças ocorridas na política previdenciária brasileira resultaram num aumento significativo do número de pedidos de aposentadoria de servidores na UFPR. Com o objetivo de promover um repensar sobre essa fase da vida e de preparar para o processo de aposentadoria, foi criado em 1995, junto a Pró-Reitoria de Recursos Humanos e Assuntos estudantis (PRHAE), em parceria com o Departamento de Psicologia, o Programa de Preparação para a Aposentadoria (PPA). A intervenção ocorreu em dois níveis, um institucional e outro grupal, tendo como foco aqueles servidores que se encontravam dois anos antes de sua aposentadoria. Foi realizada uma pesquisa de campo junto à população-alvo potencial que justificou e subsidiou a programação da intervenção junto aos grupos denominados Grupos de Orientação para Aposentadoria (GOPA). As estratégias de intervenção voltaram-se para níveis de sensibilização, informação e instrumentalização-reflexão sobre o significado deste momento de transição. Os resultados apontaram a impor-

${ }^{1}$ Acadêmicos de Psicologia - UFPR.

2 Professora do Departamento de Psicologia da UFPR. Praça Santos Andrade, 50 $1^{\circ}$ andar - 80020-300 - Curitiba - PR - E-mail: ybulgacov@ hotmail.com. 
tância da continuidade do programa e sua sistemática ampliação confrontando com uma cultura imediatista e de não prevenção, mas que efetivamente ofereça possibilidades de promoção de qualidade de vida e crescimento pessoal.

Palavras-chave: aposentadoria, envelhecimento, qualidade de vida.

\section{RETIREMENT PREPARATION PROGRAM: A HUMAN DEVELOPMENT POLICY}

\section{ABSTRACT}

Currently, the aging process of the world's population has awoken interest in the development of initiatives aimed at "senior citizens". In 1995, the changes made to Brazilian policies regarding retirement lead to a significant increase in the number of applications for retirement made by civil servants employed at the Paraná Federal University (UFPR). With the aim of encouraging people to think again about this phase of their lives and preparation for the retirement process, the Retirement Preparation Program (PPA) was set up in 1995 through the university's Department of Human Resources and Student Issues (PRHAE), in partnership with the Department of Psychology. Intervention was made at two levels, one institutional and the other through groups, with emphasis on those employees who were two years away from retirement. Field research was done with the potential target audience and this research served to justify and fundament the scheduling of the intervention activities with groups called Retirement Guidance Groups (GOPA). Intervention strategies were aimed at awareness-raising, information, preparation and reflection on the meaning of this moment of transition. The results highlighted the importance of continuing with the program and its systematic expansion, in contrast with a culture based on the "here and now" and unconcerned with prevention, effectively offering possibilities of improved quality of life and personal growth.

Key-words: retirement, aging, quality of life. 


\section{INTRODUÇÃO}

Ao se depararem com dados referentes à idade de seus funcionários e as estatísticas de aumento de tempo de vida da população, empresas privadas e públicas começam a repensar os conceitos referentes à aposentadoria e ao envelhecer. Sabe-se hoje que é necessário mudar a atual mentalidade para uma visão mais positiva, já que o envelhecimento da população mundial é uma realidade. Este artigo discute mitos e realidades desses processos, distinguindo tais conceitos, preconceitos existentes e a formação da identidade pessoal e profissional vigentes. Através da visão social de supervalorização do trabalho, este artigo apresenta, também, o porquê da necessidade de se repensar os processos de aposentadoria considerando a valorização integral do ser humano. Apresenta, além disso, a importância de projetos auxiliares de preparação para a aposentadoria como veículos potencializadores da dimensão humanizante. Entre esses processos, será abordado o trabalho que vem sendo realizado dentro da Universidade Federal do Paraná e suas atuais abrangências.

\section{BASE TEÓRICA}

Próximo à virada de século, e também de milênio, a perspectiva de envelhecimento da população mundial tem gerado profundas transformações na sociedade, despertando o interesse no desenvolvimento de iniciativas voltadas à terceira idade.

Nos países desenvolvidos da Europa, nos Estados Unidos, Canadá, Japão, entre outros, o número de pessoas com mais de 60 anos é maior do que o de crianças e adolescentes em torno de 14 anos, já no ano 2000 (Granato, 1999). Isso eqüivale a dizer que está havendo nesses países mais avós e bisavós do que netos e bisnetos. É uma verdadeira virada demográfica; só no Brasil, há estimativas de que no ano 2025 ha- 
verá 31,8 milhões de pessoas com mais de 60 anos, sendo que uma inversão entre jovens e velhos deverá ocorrer por volta de 2050, segundo dados estatísticos da Divisão Populacional da ONU (Granato, 1999). Esse fato vem sendo igualmente estudado por Monteiro e Alves (1995), que realizaram um levantamento da população, em que a parcela de jovens com menos de 20 anos cresceu 12\% de 1980 até 1991, e a população referente a quem tem 60 anos ou mais cresceu 46\%. Isso equivale a dizer que essa população será em torno de $300 \%$ maior que a de jovens.

Pode-se dizer que esse perfil demográfico é resultado de dois fenômenos combinados: o aumento da expectativa de vida e a redução da taxa de natalidade. Essa transformação vem ocorrendo há mais tempo nas nações desenvolvidas do que entre os países emergentes, dentre os quais se inclui o Brasil. A diferença é que o ritmo desse processo, nestes países, é cada vez mais acelerado. O impacto dessas mudanças tem repercutido em vários setores da sociedade e na Previdência Social. No Brasil, a expectativa de vida atual é em torno de 69 anos, quase $50 \%$ mais que na metade do século. Já, nos Estados Unidos, onde, no início do século XX, a previsão de sobrevida era em média 47 anos, atualmente passou para uma média de 77. Entende-se como "sobrevida" o tempo de vida que ultrapassa determinado limite. É como se uma pessoa vivesse 47 anos MAIS do que previsto.

Enquanto isso, em 61 países, o número de bebês que nascem a cada ano já é inferior ao necessário para repor o atual nível populacional (Granato, 1999). Esses dados estatísticos trazem uma realidade premente: a necessidade de se repensar a juventude e a velhice constantemente, elaborando diferentes significados que levem em conta o contexto histórico da época. Birman (1995) alerta para o fato de que esta situação é construída historicamente, o que implica uma ética, polí- 
tica e estética da existência, ou seja, está inserida em um campo de valores.

Segundo o mesmo autor, o conceito de velhice passa a fazer sentido a partir do século XVIII, quando a ciência inaugura a ideologia do evolucionismo, fundando a transformação humana em processos biológicos, e, conseqüentemente, delimitando diferentes fases de desenvolvimento: nascer, crescer, envelhecer e morrer. $O$ conceito também situa o homem num contexto histórico e, dessa forma, a existência humana passa a ser representada nas dimensões do tempo e da história.

Além dessa conceituação, faz-se importante a distinção que Sais (1995) apresenta a respeito de três conceitos aí envolvidos: o de velhice, o de envelhecer e o de velho. Velhice seria um conceito genérico-abstrato no qual estão incluídas as pessoas com 60 anos ou mais; o envelhecimento é um processo que se dá desde o nascimento até a morte, em qualquer idade; e o velho seria a pessoa, singularidade inscrita num período histórico, com desejos e significações próprias. É fato freqüentemente observado na fase da "3. " idade ", quando uma sensação de vazio, de inutilidade e de exclusão acomete um número significativo de pessoas. Isso acaba acontecendo porque, na sociedade atual, a valorização do indivíduo é baseada no quanto ele produz. Em outras palavras, o seu valor é determinado segundo a sua capacidade de trabalho produtivo. Hoje, esse indivíduo não tem tempo para refletir a respeito de si mesmo e de suas questões, o que dificulta sua comunicação tanto no âmbito familiar quanto no social. Neri (1998) coloca que as pessoas precisam se conhecer novamente, saber que podem viver de maneira independente para não cair em mitos ou modelos de envelhecimento que muitas vezes se perdem na noção de virilidade, na prática de esportes violentos ou na aquisição de bens característicos de jovens. Caso contrário, o indivíduo vai, durante toda sua vida, assumir papéis impostos automaticamente pela sociedade, esquecendo-se de refletir 
sobre eles. Essa reflexão é fundamental para que o sujeito possa elaborar suas questões a respeito da velhice de forma realista, relacionado-as com o processo de aprendizagem permanente e permitindo-se compreender a necessidade de um maior equilíbrio entre o trabalho e o desfrute. Preocupado com essa questão, Bernhoeft (1991) apresenta 7 tipos de papéis assumidos pelos profissionais, no que diz respeito ao tempo dedicado efetivamente à empresa; o profissional paralelo que se dedica a outras atividades - remuneradas ou não - mas que tem como significado uma extensão do trabalho; o conjugal, cujo tempo é destinado à convivência com o(a) parceiro(a); o familiar, destinado aos filhos e pais; o social, destinado a amigos e pessoas de sua estima; o educacional, que envolve tudo o que se destina a contribuir para o crescimento intelectual e pessoal; e, por último, o recreacional, assim chamado quando destina algum tempo para si mesmo.

As pessoas aprenderam que devem ter sempre alguma atividade - primeiro estudar e depois trabalhar - o importante é fazer alguma coisa, nem que para isso se deixe de ver o filho nascer ou crescer. Primeiro vem o trabalho, a produção. Outro aspecto aterrador aparece quando o indivíduo pára para ouvir o próprio discurso: cerca de $90 \%$ do que se fala está centrado num futuro almejado, nunca concreto, como: “...quando eu entrar em férias...”, "...quando eu ganhar na loto...”. Na verdade idealiza-se o que fazer (e que dificilmente acontece), esquecendo-se do presente. A respeito disso, Bernhoeft (1991) completa que, geralmente, as expectativas centradas nesse futuro refletem uma insatisfação com a situação presente, tanto no nível pessoal como no profissional.

Com o advento da aposentadoria, ocorre uma série de mudanças implicadas nesse processo, e o indivíduo adquire um novo status econômico, político e social. 
Caldas (1997) lembra-nos de um fator muito importante: o cidadão é velho não só porque seu organismo está em processo de declínio biológico mas, sobretudo, porque assim é decretado. Um exemplo que vem a confirmar esse tipo de visão é apresentado por Neri (1998), quando mostra um levantamento realizado dentro de empresas sobre a idade a partir da qual o trabalhador era considerado velho; constatou, de modo impressionante, que, a partir dos 40 anos, o trabalhador já levava o rótulo de velho.

Em síntese, verifica-se uma mudança significativa na vida do indivíduo. Segundo Zanelli (1992), grande parte de sua identidade e de seu status social dependem do papel profissional que a pessoa exerce. Afirma Santos (1991), "a exclusão do mundo do trabalho é ao mesmo tempo perda de lugar no sistema de produção, reorganização espacial e temporal da vida do sujeito, e reestruturação de identidade pessoal. A aposentadoria obriga o sujeito a reorganizar as identificações habituais, que estruturam o eu" (p. 2)

\section{CONTEXTUALIZANDO O PROGRAMA DE PREPARAÇÃO DA APOSENTADORIA (PPA) NA UFPR}

Foi com o objetivo de trabalhar essas questões e, diante do aumento significativo do número de pedidos de aposentadoria decorrentes da política previdenciária anunciada pelo governo nesta época, que, em 1995, a Pró Reitoria de Recursos Humanos e Acadêmicos e o Departamento de Psicologia da Universidade Federal do Paraná, através do estágio de Psicologia Organizacional, criou o Programa de Preparação para Aposentadoria (PPA).

Esse programa, embora estruturado inicialmente nos moldes do programa de preparação que vinha sendo realizado na Universidade Federal de Santa Catarina (Esper; Santos, Pinheiro \& Oliveira, 1993), desenvolveu-se na Pró- Reitoria de 
Recursos Humanos e Assuntos Acadêmicos como parte de um programa institucional maior: o Programa de Participação Permanente voltado à promoção contínua do desenvolvimento adulto, ser humano ativo, portador de potencialidades de realizações pessoais e sociais, como fim principal de seus atos numa permanente construção da cidadania.

\section{A PESQUISA}

O trabalho teve início com o levantamento junto ao público alvo, através de entrevistas, a respeito de diversos tópicos sobre a aposentadoria, dentre eles: o nível de informação com relação ao processo de aposentadoria (como ocorre, quais as vias administrativas, entre outras informações); a avaliação do serviço prestado pela Universidade com relação à aposentadoria; o nível de informação proporcionada aos servidores sobre os trabalhos relacionados com a questão da aposentadoria; o projeto de vida para o período posterior à aposentadoria; as expectativas com relação a um programa voltado à preparação para a aposentadoria.

Como resultado dessa pesquisa, foram observados muitos dos problemas já descritos por vários autores como: falta de perspectiva para o futuro de recém-aposentados e desejo de reverter a aposentadoria; aumento do número de doenças como depressão, complicações orgânicas, e até mesmo óbito entre recém-aposentados que, antes da aposentadoria, gozavam de boa saúde (Silva, A.; Silva, L. \& Santos, 1998).

A análise específica dos dados coletados na pesquisa favoreceu o planejamento das demais atividades que se desenvolveram na seqüência. Da pesquisa, realizada no ano de 1999, que teve uma amostragem de $33 \%$ da população do nível grupal, emergiram importantes considerações.

A primeira questão da entrevista (De 0 a 10, O que você sabe sobre o processo de aposentadoria? - Como ocorre, 
quais as vias administrativas, entre outras informações) obteve uma distribuição que apontou uma realidade alarmante.

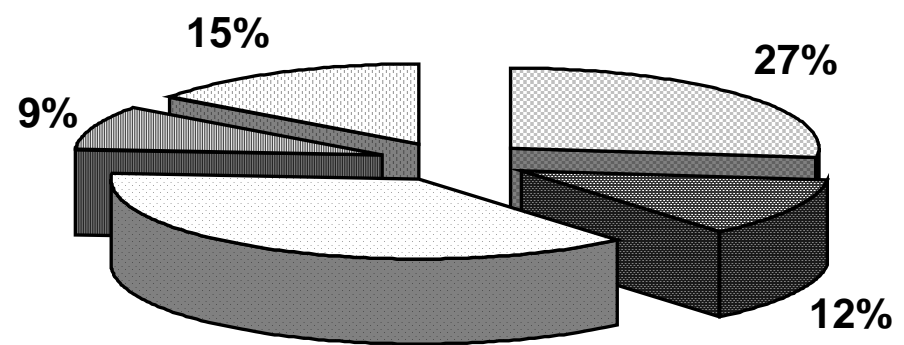

$37 \%$

Muito pouco: entre 0 e 2

Pouco: entre 3 e 4

$\square$ Médio: entre 5 e 6

(口) Bastante: entre 7 e 8

$\square$ Total: entre 9 e 10

Figura 1: Distribuição do percentual de servidores de acordo com a pontuação atribuída à questão 1 da entrevista.

A média da avaliação de conhecimento do público-alvo foi de 4,5. Verificou-se o significativo nível de desinformação em que se encontrava grande parte do público-alvo, que representava $76 \%$ (somando os grupos com pontuação entre 0 e 6). Apenas $24 \%$, uma minoria, estava segura com relação às informações que deveria saber sobre o seu processo de aposentadoria. Sabendo-se que o período prévio à aposentadoria, em geral, é vivenciado com uma relativa ansiedade, verificouse que ele acaba sendo agravado pela natural insegurança que pode ser despertada em função do desconhecimento. O que sentir quando nem se sabe que documentação deve ser providenciada, quanto tempo de serviço se tem, e como ficará a si- 
tuação econômica depois de aposentado? Questões como estas foram relatadas por alguns dos entrevistados.

Esse perfil de desinformação também foi verificado com relação aos trabalhos (programas) proporcionados pela UFPR, voltados a esse público-alvo. No entanto, com uma distribuição, como pode ser observada, ainda menos positiva.

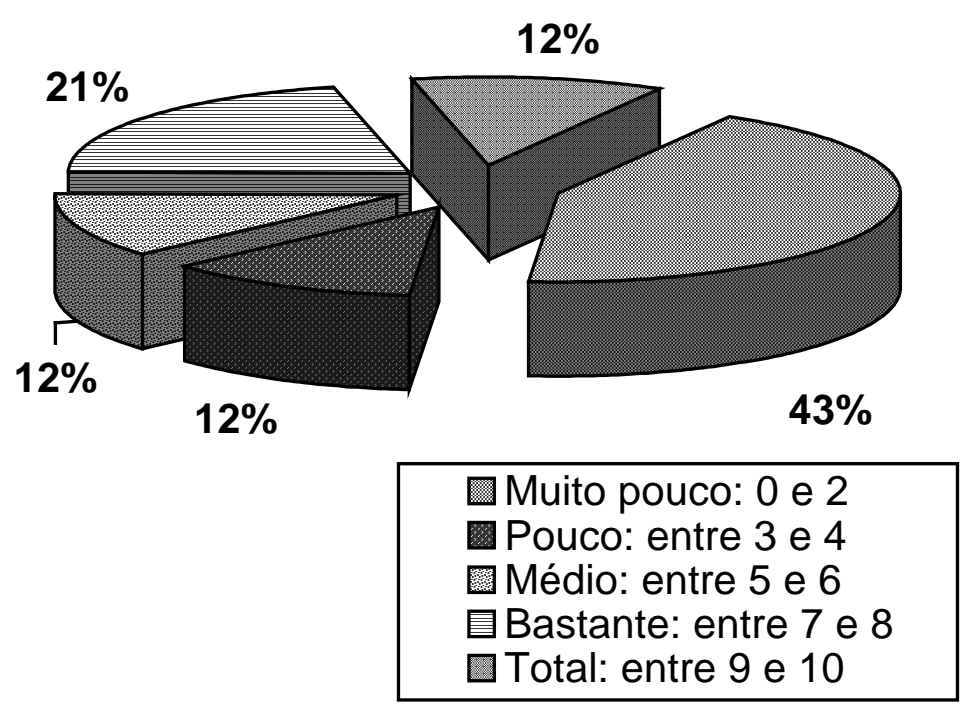

Figura 2: Distribuição do percentual de servidores de acordo com a pontuação atribuída à questão 3 da entrevista

$\mathrm{Na}$ terceira questão (De 0 a 10, o que você sabe a respeito dos trabalhos relacionados com a questão da aposentadoria, proporcionados aos servidores da UFPR?) a média da pontuação das respostas foi 4 . Verificou-se que $55 \%$ conhecia pouco ou muito pouco sobre os trabalhos oferecidos. Em outras palavras, mais da metade mal sabia o que a Universidade tem proporcionado aos servidores em vias de se aposentarem ou aposentados. 
Voltando o foco de análise para o tipo de informação que o servidor teria interesse em receber, a segunda questão da entrevista (Que informações você espera que seu Departamento lhe ofereça a respeito do processo de aposentadoria?) trouxe dados importantes.

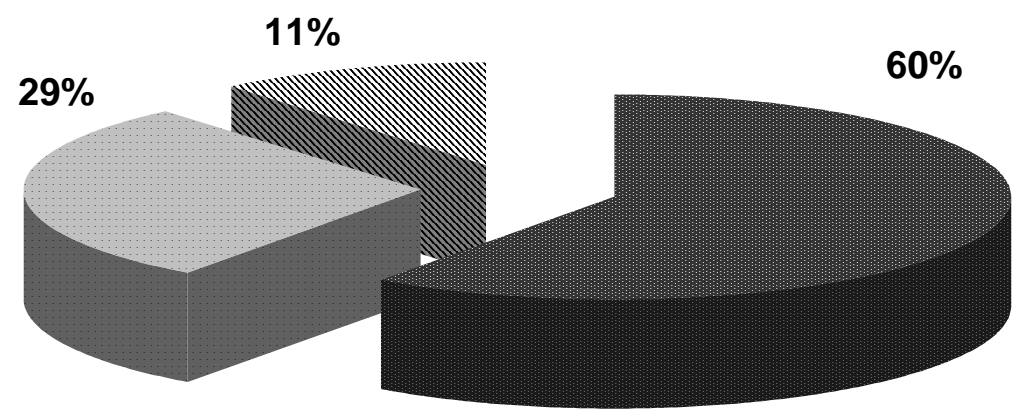

C1: Burocrático - legislação, questões salariais, tempo de serviço, perdas e vantagens, recolocação ocupacional

C2: Outros: processos pessoais de aposentadoria, críticas à falta de informações burocráticas e referentes aos PPAs, orientação psicológica

NC3: Nenhuma informação

Figura 3: Distribuição do percentual de servidores de acordo com a pontuação atribuída à questão 2 da entrevista

Ficou evidente que mais da metade do público-alvo desejava receber informações burocráticas e legais com relação ao seu processo de aposentadoria. Em torno de $29 \%$ teria interesse em saber alguns aspectos mais pessoais com relação ao seu processo de aposentadoria; queria uma orientação psicológica; ou fazia críticas à falta de informação. 
Entre as pessoas entrevistadas, os servidores que avaliavam não ter muito conhecimento, queixavam-se de não poder deixar o seu trabalho para virem se informar na PRHAE.

Apesar de existir uma unidade na PRHAE, responsável pela devida orientação do público-alvo, verificou-se um significativo nível de desinformação por parte dos interessados. Esse fato levantou a suspeita de um distanciamento muito grande entre os servidores e a unidade. Tal problema poderia estar relacionado, entre outros fatores, ao processo de burocratização característico da instituição, e por conseguinte, à sua cultura organizacional.

Os aspectos levantados configuraram um dos focos de trabalho que foram desenvolvidos no programa. Num primeiro nível de atuação, o fator informação poderia ser trabalhado com a orientação, através da unidade responsável na PRHAE. Para tanto, a intervenção desenvolvida no programa incluiu reuniões com chefias das unidades envolvidas para apresentação dos dados da pesquisa, visando à discussão de propostas de melhoria e humanização dos processos administrativos de aposentadoria. $O$ ponto de partida dessas propostas focou a análise das possibilidades de se realizar uma redução da distância entre os serviços prestados pelo setor de recursos humanos e o servidor.

Relacionada com os dados apontados na questão 2 da entrevista, outra consideração foi levantada. Os dados vieram a corroborar a impressão de que, quem se encontra no período prévio à aposentadoria costuma estar no auge de sua carreira, e, muitas vezes, sua única preocupação com a aposentadoria, refere-se a aspectos financeiros e jurídicos. Acontece que essa mesma pessoa, após aposentada, é afastada de sua atividade de tantos anos e percebe que conviveu muito pouco com a família, que não soube ocupar seu tempo com lazer e que desenvolveu muito pouco "fontes de prazer" para sua vida, além do trabalho. 
A questão 5 , elaborada para investigar a representação social da aposentadoria ( $\mathrm{O}$ que você pensa a respeito da aposentadoria?), também trouxe dados relevantes. A análise de discurso elaborada permitiu verificar a presença de idealizações e estereótipos, tanto nas visões pessimistas quanto nas otimistas, assim como, um processo de negação da aposentadoria. Entre as visões otimistas, servidores relataram que, depois da aposentadoria, iriam fazer tudo aquilo que não fizeram em toda a sua vida. Entre as visões pessimistas, houve servidores que relacionaram a aposentadoria com doença, abandono e morte. $O$ processo de negação foi levantado a partir de discursos como "eu ainda não pensei sobre o assunto", "acho que ainda é cedo para pensar nisso". É importante frisar que esses servidores faziam parte do grupo que se aposentaria no período de 2 anos. A análise de discurso das respostas apresentadas à questão 7 , elaborada para investigar a representação social da velhice ( $O$ que você pensa a respeito da velhice?), também revelou algumas idealizações e estereótipos, assim como um processo de negação.

\section{A INTERVENÇÃO}

Considerando essa realidade, os objetivos traçados para o programa visavam: 1) promover um repensar da velhice e dos processos de aposentadoria, através de uma valorização integral do ser humano. 2) desmistificar o processo de envelhecimento nas instâncias da Universidade. 3) preparar para a aposentadoria, em níveis de sensibilização, informação e instrumentalização. 4) investigar e incitar o interesse na criação de parcerias entre o PPA e os departamentos da Universidade, para o desenvolvimento de programas específicos relacionados com a temática. 5) investigar e desenvolver nas instâncias responsáveis, a melhoria e humanização dos procedimentos administrativos referentes à aposentadoria. 
A intervenção planejada foi caracterizada em dois níveis: num nível mais amplo (institucional), envolvendo todos os servidores; e num nível mais estrito (grupal), os técnicos administrativos e docentes, com possibilidade de aposentadoria num período de dois anos, bem como os recém-aposentados.

Foram desenvolvidos, no programa, encontros grupais denominados Grupo de Orientação para a Aposentadoria (GOPA), espaço de reflexão a respeito das diversas implicações da aposentadoria, no qual cada participante pôde descobrir formas mais adequadas de lidar com esse momento, podendo vivenciar uma melhoria de sua qualidade de vida. Essa atividade incluiu palestras envolvendo profissionais de diversas áreas, nas quais foram discutidos temas como saúde e cuidados médicos, cuidados com a alimentação, orientações burocráticas e legais, entre outros. Também foram realizadas algumas dinâmicas de grupo, visando a uma antecipação do momento de aposentadoria, planejamentos futuros, e representação de velhice e aposentadoria. Com tudo isso, além da sensibilização (que envolveria a motivação do participante) e da informação, possibilitou-se a instrumentalização, na medida em que são trabalhados comportamentos, habilidades, desempenhos e emoções.

A fim de promover uma continuidade e extensão desse processo de preparação para a aposentadoria, a intervenção desenvolvida também incluiu reuniões sistemáticas com representantes do Programa de Participação Permanente (PPP). Esse trabalho tem investido igualmente, na criação de futuras parcerias com outros programas voltados à mesma temática, dentre eles um programa de extensão da "Terceira Idade". Busca também a realização de trabalho multidisciplinar com outros departamentos. 


\section{CONSIDERAÇÕES FINAIS}

Os resultados obtidos com as inúmeras intervenções desenvolvidas até o ano de 1999 têm demonstrado que os objetivos de trabalhar diretamente com o público-alvo através da sensibilização, informação e instrumentalização vêm sendo, por um lado, atingidos, e por outro, não. As pessoas que participam do processo, avaliam-no de forma extremamente positiva (avaliação de reação), entretanto, por outro lado, observa-se uma baixa participação do servidor em relação ao número total de aposentandos. O programa é oferecido a cada semestre, e a média de participação é de dez servidores em contraposição à de 200 servidores-aposentados. Este quadro observado gera importantes questões do ponto de vista da psicologia da organização e do trabalho, em especial para atividades voltadas para a prevenção. Práticas voltadas a uma política de desenvolvimento humano permanente (e preventivo) que contribuem para a futura qualidade de vida dos envolvidos confrontam-se com a necessidade de uma "mudança de mentalidade" referente à velhice e seus processos, e a uma cultura imediatista não sensível, ainda, às atividades preventivas. Eis o desafio.

A atuação voltada à problemática da aposentadoria requer, ainda, um árduo trabalho interdisciplinar, em que 0 aspecto psicossocial apresente um caráter de destaque. Segundo Moragas, 1988 (citado em Zanelli, 1992), "a preparação para a aposentadoria constitui um processo de informação-formação para que as pessoas aposentadas assumam seu novo papel positivamente: beneficia aos interessados e à sociedade, minimiza custos remediativos e sociais, melhora a saúde física, psicológica e social da pessoa" (p. 3). O autor ainda salienta que a preparação para aposentadoria constitui o instrumento mais efetivo em custo e tempo para configurar esta nova posição social do aposentado. 


\section{REFERÊNCIAS BIBLIOGRÁFICAS}

Bernhoeft, R. (1985). Administração do tempo: um recurso para meIhorar a qualidade de vida pessoal e profissional. São Paulo: Nobel.

Bernhoeft, R. (1991). Trabalhar e desfrutar: equilíbrio entre vida pessoal e profissional. São Paulo: Nobel.

Birmam, A. (1995). Futuro de todos nós: temporalidade, memória e terceira idade na psicanálise. Em A. S. Veras (org), Terceira idade: um envelhecimento digno para o cidadão de futuro (p. 29-48). Rio de Janeiro: Relume - Dumará - UnATI/UERJ

Camargo, R; Budel, P \& Maia, L. (1997). Relatório de Estágio em Psicologia Organizacional, não publicado. Departamento de Psicologia da Universidade Federal do Paraná.

Castro, A. P; Carpanezzi, M. M.; Abdullah, S \& Moraes, S. D. (1996). Relatório de Estágio em Psicologia Organizacional, não publicado. Departamento de Psicologia da UFPR.

Caldas, C. P. (1997). Memória, trabalho e velhice: um estudo das memórias de velhos trabalhadores. Em A. S. Veras (Org), Terceira idade: desafios para o terceiro milênio (p. 15-40). Rio de Janeiro: Relume - Dumará - UnATI/UERJ.

Esper, A ; Santos, M ; Pinheiro, J \& Oliveira, K. (1997). Projeto de Estágio: Programa de Preparação para a Aposentadoria, não publicado. Centro de Ciências Humanas e Filosofia da Universidade Federal de Santa Catarina.

Granato, A. (1999, 10 mar.). O planeta grisalho. Revista Veja, 68-70.

Neri, A. (1998). A preparação para a aposentadoria. Revista A Terceira ldade, 15, 19-27.

Pereira, E. A; Cagneti, F. S. (1995). Relatório de Estágio em Psicologia Organizacional: Programa de Preparação para a Aposentadoria dos Servidores da Universidade Federal do Paraná, não publicado. Departamento de Psicologia da UFPR.

Knechtel, M. R. (1997). Programa de participação permanente: princípios, critérios e procedimentos VI - Subprograma de Preparação para a Aposentadoria. Curitiba: Editora da UFPR.

Santos, M. F. S. (1991). Identidade e Aposentadoria. São Paulo: EPU.

Silva, A de L.; Silva L. F. C. da \& Santos, R. S. (1998). Relatório de Estágio em Psicologia Organizacional: Programa de Preparação para a Aposentadoria, não publicado. Departamento de Psicologia da UFPR.

Zanelli, J. C. (1992). Uma investigação preliminar das expectativas dos servidores da UFSC quanto à aposentadoria, não publicado. Universidade Federal de Santa Catarina. Departamento de Psicologia. 